\title{
INDOOR CARBON DIOXIDE CONCENTRATIONS, VOCS, ENVIRONMENTAL SENSITIVITY ASSOCIATION WITH MUCOUS MEMBRANE AND LOWER RESPIRATORY SICK BUILDING SYNDROME SYMPTOMS IN THE BASE STUDY: ANALYSES OF THE 100 BUILDING DATASET
}

\author{
MG Apte and CA Erdmann
}

\begin{abstract}
Using the 100 office-building Building Assessment Survey and Evaluation (BASE) Study dataset, we performed multivariate logistic regression analyses to quantify the associations between indoor minus outdoor $\mathrm{CO}_{2}\left(\mathrm{dCO}_{2}\right)$ concentrations and mucous membrane $(\mathrm{MM})$ and lower respiratory system (Lresp) Sick Building Syndrome (SBS) symptoms, adjusting for age, sex, smoking status, presence of carpet in workspace, thermal exposure, relative humidity, and a marker for entrained automobile exhaust. Using principal components analysis we identified a number of possible sources of 73 measured volatile organic compounds in the office buildings, and assessed the impact of these VOCs on the probability of presenting the SBS symptoms. Additionally we included analysis adjusting for the risks for predisposition of having SBS symptoms associated with the allergic, asthmatic, and environmentally sensitive subpopulations within the office buildings. Adjusted odds ratios (ORs) for statistically significant, dose-dependant associations $(\mathrm{p}<0.05)$ for dry eyes, sore throat, nose/sinus congestion, and wheeze symptoms with 100-ppm increases in $\mathrm{dCO}_{2}$ ranged from 1.1 to 1.2 . These results suggest that increases in the ventilation rates per person among typical office buildings will, on average significantly reduce the prevalence of several SBS symptoms, up to $80 \%$, even when these buildings meet the existing ASHRAE ventilation standards for office buildings. VOC sources were observed to play an role in direct association with mucous membrane and lower respiratory irritation, and possibly to be indirectly involved in indoor chemical reactions with ozone that produce irritating compounds associated with SBS symptoms. O-xylene, possibly emitted from furniture coatings was associated with shortness of breath (OR at the maximum concentration $=8, p<0.05)$. The environmental sensitivities of a large subset of the office building population add to the overall risk of SBS symptoms (ORs ranging from 2 to above 11) within the buildings.
\end{abstract}

\section{INDEX TERMS}

Sick building syndrome, Ventilation, Carbon dioxide, Logistic regression, BASE study.

\section{INTRODUCTION}

Understanding the multifactorial etiology of sick building syndrome (SBS) in office buildings has been a major challenge. SBS is used to describe a set of symptoms with unidentified etiology frequently reported by workers in office buildings. The individuals who suffer from SBS report that the symptoms occur when they spend time indoors, particularly in office buildings, and that the symptoms lessen while away from the building (Levin, 1989; Mendell, 1993). Evidence for the hypothesis that building characteristics and resultant indoor environmental quality affects health outcomes continues to accumulate (Mendell, 1993; Fisk, 2000). These health outcomes include SBS symptoms, allergy and asthma symptoms, and respiratory illnesses. Indoor air quality also appears to influence rates of absence, work 
performance, and health care costs (Fisk, 2000). In this paper, we concentrate on buildingrelated upper respiratory and mucous membrane (MM) symptoms (i.e., irritated eyes, throat, nose, or sinus), and lower respiratory (LResp) irritation (i.e., difficulty breathing, tight chest, cough, or wheeze). We explore, in a dataset collected in 100 US office buildings, the contributions to these symptoms due to indoor concentrations of volatile organic compounds (VOCs), building ventilation based on occupant-generated indoor carbon dioxide $\left(\mathrm{CO}_{2}\right)$ concentrations, while controlling for a variety of potentially confounding individual-level and environmental variables.

\section{VOCs and SBS symptoms in the literature}

Although VOCs are suspected to be significant contributors to SBS, field studies to demonstrate this relationship have not generally been supportive. Ten Brinke, et al. (1998) reported a new approach for developing VOC metrics. These were statistically significant predictors of SBS symptoms reported in the California Healthy Buildings Study. In particular, Principal Component Analysis (PCA) was used to group correlated VOCs into a reduced set of Principal Component vectors (PCs) that are associated with sources. The PCs were then used in a logistic regression analysis to estimate the association between SBS symptoms and the VOC exposure metrics, while adjusting for other building environmental and occupantrelated covariates. This approach, in addition to regression using individual VOC measurement, was recently applied in models to study the association of VOCs with selfreported SBS symptom data in a 28-building subset of the Building Assessment Survey and Evaluation (BASE) study (Apte and Daisey, 1999). The BASE study was conducted by the U.S. EPA in a probability sample of 100 large U.S. office buildings

\section{$\mathrm{CO}_{2}$ and SBS Studies in the Literature}

At concentrations occurring in most indoor environments, $\mathrm{CO}_{2}$ buildup can be considered as a surrogate for other occupant-generated pollutants, particularly bioeffluents, and for ventilation rate per occupant, but not as a causal factor in human health responses. The primary source of $\mathrm{CO}_{2}$ in office buildings is respiration of the building occupants. $\mathrm{CO}_{2}$ concentrations in office buildings typically range from 350 to $2,500 \mathrm{ppm}$ (Seppänen et al., 1999). The Threshold Limit Value for 8-hour time-weighted-average exposures to $\mathrm{CO}_{2}$ is $5,000 \mathrm{ppm}$ (ACGIH, 1991). Currently, the American Society of Heating, Refrigeration, and Air-conditioning Engineers (ASHRAE) recommends a minimum office building ventilation rate offices of $10 \mathrm{Ls}^{-1}$ per person, corresponding to an approximate steady state indoor concentration of $870 \mathrm{ppm}$ (ASHRAE, 1999), based on the assumptions that outdoor $\mathrm{CO}_{2}$ is $350 \mathrm{ppm}$ and indoor $\mathrm{CO}_{2}$ generation rate is $0.31 \mathrm{Lmin}^{-1}$ per person.

In a recent review (Seppänen et al., 1999), about one-half of 22 studies of SBS symptoms in office buildings found that increased indoor $\mathrm{CO}_{2}$ levels were positively associated with a statistically significant increase in the prevalence of one or more SBS symptoms. SBS symptoms associated with $\mathrm{CO}_{2}$ included headache, fatigue, eye symptoms, nasal symptoms, respiratory tract symptoms, and total symptom scores. Seventy percent of studies of mechanically ventilated and air conditioned buildings found a significant association between

an increase in $\mathrm{CO}_{2}$ and SBS symptoms. Building ventilation rates were also associated with SBS symptoms. An analysis of the 94-96 BASE dataset found statistically significant doseresponse relationships between $\mathrm{dCO}_{2}$ and the following symptoms: sore throat, irritated nose/sinus, combined mucous membrane symptoms, tight chest, and wheeze; the adjusted 
odds ratios for these symptoms ranged from 1.2 to 1.5 per 100 ppm increase in $\mathrm{dCO}_{2}($ Apte et al., 2000).

\section{METHODS}

\section{The BASE Study}

The data analyzed in this paper were collected in 100 randomly selected large U.S office buildings from 1994 to 1998 by the U.S. Environmental Protection Agency for the Building Assessment Survey and Evaluation (BASE) study (Girman et al., 1995; Womble et al., 1996). These buildings were all at least partially mechanically ventilated and all but one was air conditioned. BASE buildings were studied during one-week periods either in winter or summer. Environmental data were measured during the week of questionnaire administration. The BASE protocol is discussed fully elsewhere (Womble et al., 1993; BASE Website).

The BASE questionnaire confidentially collected occupant information, including sex, age, smoking status, job characteristics, perceptions about the indoor environment, and health and well-being. The SBS symptoms elicited from the questionnaire included: chest tightness, difficulty breathing, cough or wheezing; fatigue; headache; eyestrain; and dry or itchy skin. In this study we restrict our analyses to the mucous membrane (irritation of eyes, nose, and throat) and lower respiratory (chest tightness, difficulty breathing, cough or wheezing) SBS symptoms. To qualify as a SBS symptom in the analyses presented here, the occupant must have had a reported a symptom occurrence at least 1-3 days per week during the month previous to the study and the particular symptom must have shown improvement when the occupant was away from work. Additionally, these symptoms are analyzed both individually and in combined categories: Mucous Membrane $(\mathrm{MM})=$ at least one of irritation of eyes, stuffy nose/sinus, and sore throat; Lower Respiratory (Lresp) = at least one of chest tightness, shortness of breath, cough or wheezing.

Select BASE questionnaire responses were used to identify potentially sensitive subpopulations within the study. The variables used for this purpose include previously diagnosed dust allergy, mold allergy, hayfever, eczema, asthma, and migrane. Self-reported sensitivity to (environmental) tobacco smoke and chemical sensitivity were also considered. These variables were used individually in some models but were combined in other models (one or more allergy or hayfever into a single allergy variable; one or more chemical or tobacco sensitivity into a single sensitivity variable; and one or more of any of the above variables into a general potentially predisposing conditions variable).

At each office building, $\mathrm{CO}_{2}$, carbon monoxide (CO), VOCs temperature, and relative humidity (RH) were measured at three indoor locations and outdoors. $\mathrm{CO}_{2}$ and indoor temperature were collected as 5-minute averages. VOC samples using both canister and multisorbent tube collection methods were collected and analyzed by gas chromatographmass spectrometry for up to 73 VOC species, of which 36 VOC compounds were analyzed and detectable for at least 41 buildings (Table 1). Formaldehyde (100 buildings) and acetaldehyde ( 86 buildings) samples were collected and analyzed as well. Spatial-average pollutant concentrations and average temperatures were calculated based on data from the three measurement sites. Time-averaged $(8 \mathrm{hr})$ workday difference between indoor and outdoor $\mathrm{CO}_{2}$ concentrations $\left(\mathrm{dCO}_{2}\right)$ was calculated as a surrogate measure of ventilation rate per occupant. Time averaged indoor minus outdoor $\mathrm{CO}$ data (deltaCO) were also calculated 
for each building. One-day average $\mathrm{dCO}_{2}, 18 \mathrm{VOCs}$, formaldehyde, deltaCO, temperature, and RH were available for all 100 buildings.

A thermal exposure variable $\left({ }^{\circ} \mathrm{C}\right.$-hours) was calculated as the integrated difference between 5minute-average-temperature and $20^{\circ} \mathrm{C}$, normalized to 10 hours of exposure. The indoor workday-average relative humidity $(\mathrm{RH})$ was calculated.

As discussed previously (Apte and Daisey, 1999), one VOC, 1,2,4 trimethylbenzene (TMB), found in infiltrating outdoor air and originating from automotive sources, was found to have statistically significant associations with a number of MM and LResp. In the following analysis, this variable was used in models where other VOCs were not included.

\section{Statistical Methods}

Multivariate logistic regression (MLR) was used to calculate prevalence odds ratios (OR) and Wald Maximum Likelihood (WML) statistics (SAS, 1989). Crude and adjusted MLR models were constructed using continuous $\mathrm{dCO}_{2}$ data as an independent variable and an SBS symptom as the dependent variable. Covariates used in the MLR models to control for confounding were age, sex, presence of carpet in workspace, smoking status, thermal exposure, RH, and TMB. Details regarding model building can be found in Apte et al. (2000). Additionally, a "California Buildings" covariate was added to some models.

In order to assess the possible existence of a dose-response relationship between the $\mathrm{CO}_{2}$ metric and SBS symptoms, additional analyses were conducted where $\mathrm{dCO}_{2}$ was divided into five categories based upon their distributions across the 100 buildings. The $\mathrm{dCO}_{2}$ categories reflect the $10^{\text {th }}$ and $90^{\text {th }}$ percentiles of the $\mathrm{dCO}_{2}$ distribution and three bins evenly split between them. This approach was discussed in Apte et al., 2000. For the purpose of calculating the association between the SBS symptoms and $\mathrm{CO}_{2}$ level an analysis of covariance approach was taken (Selvin, 1995): dummy variables were used to represent the four highest $\mathrm{CO}_{2}$ bins. These regressions were used to assess trends for the associations between SBS symptoms and $\mathrm{dCO}_{2}$ for the four upper $\mathrm{CO}_{2}$-level building groups using the building group with the lowest $10^{\text {th }}$ percentile concentrations as the referent.

A test was conducted to assess multivariate dose-response. Additional logistic regression modelss using a single categorical $\mathrm{CO}_{2}$ variable with five levels representing the abovedefined binned- $\mathrm{CO}_{2}$ groupings were conducted. These levels were coded using the bin-mean $\mathrm{dCO}_{2}$ for each $\mathrm{dCO}_{2}$ level. The WML statistic and associated $\mathrm{p}$-value for this categorical variable was used as a measure-of-fit of the dose-response relationship for the adjusted categorical associations between $\mathrm{CO}_{2}$ measures and SBS symptoms (SAS, 1989).

The approach using PCA to derive VOC exposure metrics has been discussed thoroughly by Ten Brinke et al. (1998). In brief, the object of PCA is to convert a set of highly correlated variables (i.e., measured VOC species in office buildings), into a reduced number of uncorrelated vectors which are linearized sums (principal components) of standardized individual variables (i.e., normalized between \pm 1 ). These PCs represent source types or building materials which emit VOCs, since species originating from the same types of sources tend to co-vary in concentration from one building to the next. Some VOC species can originate from more that one source, so it is possible that they will be associated with more than one PC. Thus, the PCA method is useful because it can apportion the VOC contributions from different source groups. It should be noted that since the PCs represent particular groups 
of sources, it is likely that they correlate with other (possibly unmeasured) compounds emitted from those sources. In these analyses, PCA correlation matrix eigenvalues of the PCs were used to determine the extent of the PCs interpretability, with a cutoff criterion of $\geq 1.0$ used to determine the PCs to be kept in the analysis. PCA was run on standardized (mean=0, standard deviation=1) values of input data, and Varimax rotation was performed.

Multivariate logistic regressions (MLR; SAS, 1989) were used to assess associations between SBS symptoms and both individual VOCs and the PCA-based exposure metrics. Multivariate models were adjusted for other risk potential risk factors and confounders. The SBS symptom/environmental exposure associations are presented as odds ratios (OR). The VOC variable "TMB" was not explicitly included in models that included the PCA vectors.

\section{RESULTS}

Prior to development of new models, it was necessary to compare the results of 94-96 dataset the analysis of $\mathrm{dCO}_{2}$ association with symptoms to those of the full 100 building 94-98 dataset. This comparison did not include potentially predisposing condition variables. Table 2 provides calculated summary statistics for environmental and individual-level factors for the participants of the 94-98 BASE survey.

Table 3 provides the results from both the crude and partially adjusted logistic regression analyses for the earlier 94-96 dataset analyses (Apte et al., 2000) and the 100 building 94-98 dataset which used the same covariates as the earlier model (see table 2). The $\mathrm{dCO}_{2}$ ORs are reported in units per $100 \mathrm{ppm}$. The larger 94-98 BASE dataset analysis yielded similar findings as compared with the smaller 94-96 data set, with smaller adjusted ORs ranging from 1.1 to 1.2 per 100 ppm increase in $\mathrm{dCO}_{2}$ for Sore Throat, Nose/Sinus, and Wheeze. The effect for dry eyes observed in the smaller 94-96 dataset was not apparent in the larger 94-98 dataset. Preliminary analyses investigated why the results obtained from the larger 94-98 dataset differed from those obtained from the smaller 94-96 dataset. Mean levels and standard deviations of $\mathrm{dCO}_{2}$ and the continuous covariates did not differ substantially between buildings for which data were collected in 94-96 compared with buildings for which data were collected more recently (Table 4). Of the dichotomous covariates, only the proportion of females and older occupants differed between the two data collection periods (Table 5). In terms of SBS symptom prevalences, the two data collection periods did not differ appreciably (see Table 5).

Regional differences in climate, building codes, and other factors may account for the differences in the two analyses. For example, changes in indoor smoking policies over the BASE study period may have had an impact on factors that may be associated with SBS symptoms. One way to examine the influence of regional differences is to look at the influence of buildings from different states. Because California contributed the largest proportion of recently added buildings in 1997-1998 to the BASE study (16\% by building count, $14 \%$ of the BASE study respondents), we first considered whether being an occupant in a "California Building" influenced SBS symptoms. After including the "California Building" covariate in the MLR model, the odds ratios relating $\mathrm{dCO}_{2}$ (per $100 \mathrm{ppm}$ ) to the selected SBS symptoms more closely resembled those found in the analysis of the 94-96 dataset (see Table 6). 


\section{Enhanced modeling}

The true explanation for the California Building effect could not be identified. We hypothesized that specific sensitivity or environmental risk factors might account for California occupant's additional risks of SBS in their work environment. Pearson correlation coefficients ( $r$, p-value) for the relationship between California Building and dust allergy $(0.05,0.004)$, hayfever $(0.06,0.0002)$, eczema $(0.04,0.006)$, and chemical $(0.04,0.01)$ and tobacco $(0.04,0.01)$ sensitivities were highly significant. The combined sensitive population metric was not statistically significant at the $95 \%$ confidence level $(r=0.02 . p=0.11)$. Thus, within the BASE study population, occupants of California buildings may have more conditions that increase their sensitivity to indoor contaminants. Variables representing these potentially predisposing conditions were added into the partially adjusted SBS models. The season in which the building was studied was also added. Table 7 identifies the covariates for which a statistically significant relationship with the MM and LResp symptoms was found. All of the sensitive population variables showed some significant relationships with symptoms, in particular, diagnosed asthma (LResp symptoms) and self-stated chemical sensitivity (all symptoms) were consistent predictors. Of additional interest was that the California Building effect fell out of the model when these covariates were added. The season variable was not associated with any symptom.

After including the health condition variables and season, the $\mathrm{dCO}_{2}$ variable was no longer statistically significant with the exception of sore throat (see Table 7). An inspection of the model output suggested this was due to reduced statistical power due to the added variables in the models, and an increased number of missing values caused by some of the sensitive population variables. In order to create a more parsimonious model a new variable was defined such that any individual that claimed to have one or more of the potentially predisposing health conditions was considered to be "sensitive" (ANYSENS). Results of logistic models, regressing the SBS symptoms on $\mathrm{dCO}_{2}$, and including the ANYSENS variable, with the other listed covariates, are outlined in Table 8 . The increase in sample size due to using a combined sensitivities variable is clear, as are the statistically significant associations between $\mathrm{dCO}_{2}$ and eye, nose, throat, and wheeze symptoms. Table 9 provides a comparison between the crude and adjusted associations, and also provides the ORs and 95\% confidence intervals for the female and ANYSENS variables in the model. Other statistically significant covariates in these models (see Table 8) were Age $>40$ (significant ORs ranged from 1.2 to 1.4), Current Smoker (OR range: 1.4 to 2.2), $\mathrm{RH}<20 \%$ (OR range: 1.6 to 2.0), 1,2,4 TMB (OR = 1.3 for Short Breath), and California Building (ORs: 1.4 for MM and 1.9 for nose/sinus).

\section{$\mathrm{CO}_{2}$ dose-response}

Figure 1 presents the results of the analysis of the trend between $\mathrm{dCO}_{2}$ and symptoms, after adjustment for all of the potential confounders listed in Table 8 (including ANYSENS), with the data from buildings in the lowest $\mathrm{dCO}_{2}$ bin serving as the referent. Total sample size for each symptom is also shown ( $\mathrm{N}$ range from 1404 to 1508). Visually, the plots suggest possible dose-response relationships, but usually with the OR in one binned group deviating from the expected dose-response pattern. Based on the WML tests for statistically significant trends, the following symptoms or symptom groups have a statistically significant dose response $(\mathrm{p}<0.05)$ relationship with $\mathrm{dCO}_{2}$ : MM, Dry Eyes, Sore Throat $(\mathrm{p}<0,005)$, Irritated Nose/Sinus, and Wheeze. 


\section{VOC sources in BASE buildings}

Table 1 lists the 36 VOCs, formaldehyde and acetaldehyde (VOC set) that are consistently usable for analysis. The complete VOC set corresponds with the smallest number of buildings (41), and a VOC set of 19 is available for all 100 buildings. Since the goal of this work is to assess the 100 building dataset, the smallest VOC set must be used in the regression models. However, the VOC sets are somewhat related, and information from the larger VOC sets can be used to interpret the VOC combinatorial patterns in the 100 building set - this is particularly useful, although imperfect, for interpreting principal component groupings and source identification.

We will discuss the PCA analysis results from the largest and smallest VOC sets here. The deltaCO variable was included in each analysis. Due to the large size of the principal components matrix produced by the PCA, it is impractical to tabulate the results for the larger two VOC sets. The PCA results for the 100 building VOC set are shown in Table 10. Table 11 presents a summary of primary (PC loading $\geq 0.5)$ and secondary $(0.25<$ loading $<0.5)$ PCs as well as suggested sources of the measured compounds for using the 41 building VOC set. It should be stressed that the source identifications presented in Table 11 are to be considered tentative based upon experience and a review of the literature (references are provided in the Table 11). The putative sources include: furniture coatings (1); construction materials (2); motor vehicle exhaust or possibly printing processes and printed matter (3); carpet and under-carpet (4); paints (5); draperies or fabric coverings (6); wood finishing products, wood stain (7); vinyl flooring, vinyl products (8); adhesives and automotive products possibly from attached garages (9); chlorinated materials including tap water (10); and solvents (11).

Careful inspection of the PCs from the 100 building PCA analysis (Table 10) and comparison with the source identification of the material in Table 11 provides improved certainty in assigning sources to the PCs in Table 10. Table 12 presents a cross-reference between the two analyses, and lists possible sources identified in the 100 building PCA. Thus, the 100 building PCA results may represent the following sources: furniture coatings (PC1); paint (PC2); construction materials (PC3); printing processes, printed materials (PC4); carpet, under-carpet (PC5); attached parking garage (PC6); cleaning products (PC7); vinyl flooring (PC8); unidentified formaldehyde sources (PC9); and adhesives (PC10). Only PC1 - PC7 meet the criterion for eigenvectors $\geq 1.0$ and only these are used in subsequent regression models.

\section{Logistic regression models with addition of PC vectors.}

The 100 building PCA vectors PC1 - PC7 were added to the potentially predisposed conditions-adjusted logistic regression models discussed above. The purpose was to identify associations between PCA-derived VOC (and CO) sources and the SBS symptoms. The PCA vectors were added in a forward stepwise procedure while the original covariates were forced into the models. Table 13 identifies the PCs that are associated $(\mathrm{p} \leq 0.05)$ with the SBS symptoms. Note that the association pattern for $\mathrm{dCO}_{2}$ did not change after adding the PC variables. Of interest is the positive association between PC3, the construction materials vector, and MM, dry eyes, and short breath symptoms. There is also consistent negative association between the 100 building PC5 (carpet, undercarpet) vector and symptoms (MM, LResp, and Cough). The PC6 vector (possibly attached parking garage) was negatively associated with MM and nose/sinus symptoms. 


\section{Logistic regression models with individual indoor VOCs}

Adjusted models (including ANYSENS) were constructed to explore the association between SBS and the individual VOCs from the 100 building set. These models were constructed identically to those that included the PCA vectors, with the exception that measured VOC concentrations were included instead of the PCA vectors. The VOC compounds were entered into the model using the forward stepwise selection procedure. Table 14 contains the statistically significant adjusted ORs for $\mathrm{dCO}_{2}$ (per $100 \mathrm{ppm}$ ), the VOCs (per ppb), and deltaCO.

The observed $\mathrm{CO}_{2}$ - symptom associations remain essentially unchanged. No clear patterns emerge for VOCs positively associated with symptoms. The per-ppb OR for most of the positively associated VOCs was modest, with the exceptions of o-xylene $(\mathrm{OR}=2.0$, short breath) and styrene (OR=1.4, cough). A number of VOCs (and deltaCO) were negatively associated with symptoms. The terpene compound d-limonene had a statistically significant per-ppb OR below unity in association with dry eyes, sore throat, LResp, and cough (OR ranged from 0.91 to 0.97 ). Formaldehyde was slightly negatively associated with MM, nose/sinus, and LResp (OR range from 0.96 to 0.98). Finally, deltaCO was negatively associated with MM symptoms $(\mathrm{OR}=0.81)$.

\section{DISCUSSION}

\section{$\mathrm{dCO}_{2}$ analyses}

The results of these analyses indicate an association between elevated indoor $\mathrm{CO}_{2}$ levels and increases in certain MM and LResp SBS symptoms in the 100 building BASE dataset. These findings were evident in the crude regression models and persisted through adjustment for a number of potential confounders. After adjusting for whether a building was in California, the OR for combined MM and nose/sinus symptoms also achieved statistical significance, thus highlighting the potential importance of regional effects.

Analysis of trend indicates that with the fully adjusted model, and the full 100 building dataset, a statistically significant dose-response relationship exists for the relationship between $\mathrm{dCO}_{2}$ and the MM, Dry Eyes, Sore Throat, Irritated Nose/Sinus, and Wheeze symptoms. This is consistent with the findings for the 94-98 BASE dataset as discussed in Apte et al., 2000, however the confidence intervals about the OR point estimates are considerably tighter in this study as would be expected given the larger dataset.

The odds ratios for the associations of symptoms with the maximum observed difference between indoor and outdoor $\mathrm{CO}_{2}$ concentrations may indicate the maximum potential to reduce selected SBS symptoms in typical office buildings. The maximum value of $\mathrm{dCO}_{2} \mathrm{was}$ $608 \mathrm{ppm}$. Considering only the significant associations, before controlling for the population with predisposed conditions, the ORs for the maximum value of $\mathrm{dCO}_{2}$ range from 1.8 to 4.9 . Based on these ORs, the implied potential maximum reduction in prevalence of these symptoms is roughly $80 \%$. This reduction could come through large increases in ventilation rates, improved effectiveness in providing fresh air to the occupants' breathing zone, or through identification of the symptom-causing agents in the indoor air and control of their sources. In no case were the indoor average or the peak indoor $\mathrm{CO}_{2}$ concentrations extraordinarily high; only two buildings had peak indoor (absolute) $\mathrm{CO}_{2}$ concentrations routinely above $1,000 \mathrm{ppm}$. 


\section{Sensitive Population}

The population of the office buildings predisposed to environmental sensitivity plays a very strong role in driving the prevalence of SBS symptoms. Many researchers have observed higher prevalence of SBS symptoms in women relative to men in the same buildings. ORs of about 2 are typical for the observed increased probability of SBS symptoms in females. However, this increased risk should not be considered a sensitivity per-se, more that the baseline threshold for womens' response to environmental stressors may be lower. This could be an appropriate reference to compare risks of for individuals diagnosed, or presenting themselves as being environmentally sensitive.

The ANYSENS variable shows itself to be a consistently strong and highly significant in the full BASE dataset. The lowest ORs observed in this study for risk of SBS symptoms for individuals with any of the environmental predispositions (i.e., allergies, asthma, migraine, chemical and tobacco sensitivity) are about 1.9 (after adjusting for gender and $\mathrm{dCO}_{2}$ ). The odds of an "ANYSENS" individual for having short breath in the office building are 5.5 times greater than a non-sensitive individual - the odds are 11.4 times greater for tight chest. Interestingly, the prevalence of ANYSENS in the BASE study building population is very high: $81 \%$, although the prevalence of these lower respiratory symptoms is on the order of a few percent. These observations underscore the importance of controlling the quality of the indoor environments of office workers in order to reduce the environmental conditions that trigger their response.

\section{VOCs and VOC sources}

Both individual VOC measurements and VOC source vectors were used to assess the contribution of VOCs to the SBS symptoms in this study. Due to the standardization procedure the PCA results should be interpreted with caution. The OR is defined by the ratio of odds of having a symptom, to the odds of not having it, per unit change in exposure or risk factor. For the individual VOC analyses the units are merely per- $1 \mathrm{ppb}$ increase in average concentration of a compound. In the case of the PCA-based exposure metrics where the unit change of the metric is a composite vector of standardized components, the interpretation is complicated. Nonetheless, the associations observed help provide one line of evidence regarding specific VOC sources that may be factors in SBS symptoms. The combination of identification of sources and looking at the risks associated with individual compounds emitted from those sources is informative.

In the two VOC analysis types, the compounds that were positively associated with symptoms also had belonged to PCA source vectors that were positively associated. This is also observed for the negatively associated compounds. An example is the positively associated oxylene and short breath $(\mathrm{OR}=1.95$ per $\mathrm{ppb})$, and $\mathrm{PC} 1$ (furniture coatings) and short breath $(\mathrm{OR}=1.33)$. O-xylene is the highest loading compound in the PC1 vector. From Table 1 we see that the average o-xylene concentration was $0.7 \mathrm{ppb}$ and the maximum was $3.1 \mathrm{ppb}$, distributed across the 100 buildings. At the maximum concentration, the adjusted odds ratio for short breath is $\mathrm{e}^{\left(\ln (1.95)^{* 3.1)}\right.}=7.9$. Similarly, styrene is associated with cough in Table 14 $(\mathrm{OR}=1.39)$. Interestingly, styrene loads mostly in PC3 (construction materials) that was not associated with cough. At the maximum measured average styrene level of $3.3 \mathrm{ppb}$ the odds of having cough symptoms is 3.0 .

The negatively associated significant relationship displayed consistency across the two 
analyses as well. Most striking are the d-limonene associations and PC5 associations noted above. The negative association of d-limonene and the MM and LResp symptoms was discussed in Apte and Daisey (1999). At that time the seemingly protective nature of dlimone was considered questionable. The compound is found in many substances including cleaning products, materials, air fresheners, and tobacco smoke. These PCA results suggest that some portion of it is from a carpet material source.

Current thinking suggests that d-limonene and other terpene compounds readily react with relatively common and low concentrations of ozone entrained from outdoors, and produce irritating reaction products including aldehydes and ultrafine particles (Sarwar et al., 2002; Weschler and Shields, 1999, Wolkoff et al., 2000). Thus rather than d-limonene being protective, its reaction products are antagonistic, and could lead to the associated symptoms. This tantalizing hypothesis cannot be tested without ozone data that was not collected in the BASE study.

\section{Epidemiological Considerations}

Epidemiological considerations regarding these analyses were discussed in detail in Apte et al., 2000. We refer the reader to that paper for a discussion of bias and confounding, biological plausibility, and consistency of findings in these BASE study analyses. One statistical concern is the potential impact of cross-level bias. This issue has not been addressed in the analyses presented here. The concern relates to the fact that the individual level observations within a building are not truly independent as the environments of the occupants are shared. The extent to which this bias might obscure the true relationships is thought to be small, but more sophisticated methods would be needed to verify the assumption.

\section{CONCLUSION AND IMPLICATIONS}

After adjusting for selected covariates, we found statistically significant associations of mucous membrane and lower respiratory SBS symptoms with increasing $\mathrm{dCO}_{2}$. Odds ratios for statistically significant associations of dry eyes, sore throat, nose/sinus congestion, and wheeze symptoms with $100-\mathrm{ppm}$ increases in $\mathrm{dCO}_{2}$ ranged from 1.1 to 1.2. These results suggest that increases in the ventilation rates per person among typical office buildings will, on average, significantly reduce the prevalence of several SBS symptoms, even when these buildings meet the existing ASHRAE ventilation standards for office buildings. The magnitude of the reduction will depend on the magnitude of the increase in ventilation rates, improvement in ventilation effectiveness, or reduction in sources of SBS-causing agents. Very large increases in ventilation rates, sufficient to reduce indoor $\mathrm{CO}_{2}$ concentrations to approximately outdoor levels, would be expected, on average, to decrease prevalence of selected symptoms by $80 \%$.

VOC sources may play an important role in both directly causing mucous membrane and lower respiratory irritation, and indirectly be involved in indoor chemical reactions with ozone that produce irritating compounds that can cause SBS symptoms.

The environmental sensitivities of a large subset of the office building population add to the overall risk of SBS symptoms within the buildings. This population of predisposed individuals should be considered when planning strategies to reduce SBS symptoms in office environments. 
There is no direct causal link between exposure to $\mathrm{CO}_{2}$ and SBS symptoms, but rather $\mathrm{CO}_{2}$ is approximately correlated with other indoor pollutants that may cause SBS symptoms. The BASE dataset is a valuable source of U.S building information, providing an opportunity for identification of causal factors of SBS, and for development of solutions for lowering its prevalence in buildings.

\section{ACKNOWLEDGEMENTS}

Thanks to John Girman and Laureen Burton of the US EPA Office of Air \& Radiation for the data used in this study, and Myrna Cozen, William Fisk, Al Hodgson, and Mark Mendell of Lawrence Berkeley National Laboratory for reviews. This work was supported by the Assistant Secretary of Energy Efficiency and Renewable Energy, Office of Building Technologies, State and Community Programs, U.S. Department of Energy (DOE) under Contract DE-AC03-76SF00098.

\section{REFERENCES}

ACGIH. 1991. Documentation of the Threshold Limit Values and Biological Exposure Indices, Sixth Edition, American Conference of Governmental Industrial Hygienists, Inc., Cincinnati, $\mathrm{OH}$.

Apte MG, and Daisey JM. 1999. "VOCs and "Sick Building Syndrome": Application of a New Statistical Approach for SBS Research to U.S. EPA BASE Study Data," in Proceedings of Indoor Air 99, The 8th International Conference on Indoor Air Quality and Climate, August 8-13, 1999, Edinburgh, Scotland, Vol.1, pp 117-122.

Apte MG, Fisk WJ, and Daisey JM. 2000. Associations between indoor $\mathrm{CO}_{2}$ concentrations and sick building syndrome symptoms in U.S. office buildings: An analysis of the 19941996 BASE study data. Indoor Air, 10(4):246-257.

ASHRAE. 1999. ASHRAE Standard 62-1999, Ventilation for acceptable indoor air quality, American Society of Heating, Refrigerating, and Air Conditioning Engineers, Atlanta.

BASE Website, http://www.epa.gov/iaq/largebldgs/index.html.

Bayer C. and Papanicolopoulos C. 1990. Exposure Assessments to Volatile Organic Compound Emissions from Textile Products. Proceedings of Indoor Air '90, pp.725-730.

Chang-Chuan C., Spengler J., Özkaynak H., and Lefkopoulou M. 1991. Commuter exposures to VOCs in Boston, Massachusetts. JAWMA 41:1594-1600.

Chang J. and Guo Z. 1992. Characterization of Organic Emissions from a Wood Finishing Product - Wood Stain. Indoor Air, 2:146-153.

Clausen P., Wolkoff P., and Nielsen P. 1990. Long Term Emission of Volatile Organic Compounds from Waterborne Paints in Environmental Chambers. Proceedings of Indoor Air '90, pp 557-562

Fisk WJ. 2000. Health and productivity gains from better indoor environments and their relationship with building energy efficiency. Annual Reviews of Energy and the Environment, 25:537-566.

Girman JR, Womble SE, and Ronca EL. 1995. "Developing Baseline Information on Buildings and Indoor Air Quality (BASE '94): Part II - Environmental Pollutant Measurements and Occupant Perceptions," Proceedings of Healthy Buildings '95, Milan, Italy, Vol 3, pp 1311-1316.

Kircher S., Karpe P., and Cochet C. 1993. Characterization of Volatile Organic Compounds Emission from Floor Coverings. Proceedings of Indoor Air '93, Volume 2, pp 455-460

Levin H. 1989. "Sick Building Syndrome: Review and exploration of causation hypotheses and control methods," in IAQ89 The Human Equation: Health and Comfort, Proceedings of 
the ASHRAE/SOEH Conference IAQ89, April 17-20, 1989, San Diego, CA, American Society of Heating, Refrigerating, and Air Conditioning Engineers, Atlanta, pp 263-274.

Mendell MJ. 1993. Non-specific symptoms in office workers: a review and summary of the epidemiologic literature. Indoor Air, Vol 3, pp 227-36.

Park J. Fujii S., Yuasa K., Kagi N., Toyozumi A., and Tamura H. 1996. Characteristics of volatile organic compounds in residence, Proceedings of Indoor Air '96, pp.579-584

Plehn W. 1990. Solvent Emission from Paints. Proceedings of Indoor Air '90, pp.563-568

Sack, T, Steele D., Hammerstrom, K., Remmers, J., 1992. A Survey of Household Products for Volatile Organic Compounds. Atmospheric Environment, Part A General Topics, 26(6):1063-1070.

Sarwar G., Corsi R., Allen D., and Weschler C. 2002. Production an Levels of Selected Indoor Radicals: A Modeling Assessment. In Proceedings of Indoor Air, The Ninth International Conference on Indoor Air Quality and Climate, June 30-July 5, 2002, Monterey CA.Salthammer T. 1997. Emission of Volatile Organic Compounds from Furniture Coatings. Indoor Air, 7:189-197.

SAS. 1989. SAS/STAT user's guide, Version $6,4^{\text {th }}$ ed., SAS Institute, Cary NC.

Seppänen OA, Fisk WJ, and Mendell MJ. 1999. "Association of ventilation rates and CO2 concentrations with health and other responses in commercial and institutional buildings," Indoor Air 9:226-252.

Ten Brinke, J., Selvin, S, Hodgson, A. T., Fisk, et al. 1998. Development of new VOC exposure metrics and their relationship to "Sick Building Syndrome" symptoms, Indoor Air, 8(3):140-152.

Tirkkonen T., Mttinen M. and Saarela S. 1993. Volatile Organic Compounds (VOC) from some Building and Furnishing Materials. Proceedings of Indoor Air '93, Volume 2, pp 477-482.

Wadden R., Sheff P., Franke J., Conroy 1., and Keil C. 1995. Determination of VOC Emission Rates and Compositions for Offset Printing. JAWMA, 45:547-555.

Wilkes C., Koontz M., Ryan M., and Cinalli C. 1996. Estimation of emission profiles fro interior latex paints. Proceedings of Indoor Air '96, pp.55-60.

C Weschler (2002) "Connections: Particles, Sensory Offending Filters, the "Sink" Effect and Nasal Pungency Thresholds," In Proceedings of Indoor Air, The Ninth International Conference on Indoor Air Quality and Climate, June 30-July 5, 2002, Monterey CA.

Weschler C., and Shields H. 1999 Indoor ozone/terpene reactions as a source of indoor particles. Atmos. Environ. Vol. 33, pp 2301-2312.

Wolkoff P., Wilkins C. Clausen P., and Larsen K. 1993. Comparison of Volatile Organic Compounds from Processed Paper and Toners from Office Copiers and Printers: Methods, Emission Rates, and Modeled Concentrations. Indoor Air 3:113-123.

Wolkoff P, Clausen PA, Wilkins CK et al. (2000) "Formation of strong airway irritants in terpene/ozone mixtures," Indoor Air 10: 82-91.

Womble SE, Axelrad R, Girman JR, et al. 1993. "EPA BASE Program - Collecting Baseline Information on Indoor Air Quality," Proceedings of Indoor Air '93, Vol 1, pp 821-825.

Womble SE, Ronca EL, Girman JR, et al. 1996. "Developing Baseline Information on Buildings and Indoor Air Quality (Base '95)," In IAQ 96/Paths to Better Building Environments/Health Symptoms in Building Occupants, American Society of Heating Refrigeration and Air-conditioning Engineers, Atlanta. 
TABLES

Table 1. BASE study VOC, aldehyde and carbon monoxide summary statistics for 100 BASE study buildings. Note that a total of 73 VOCs plus formaldehyde and acetaldehyde were measured in the BASE study, but the list of VOC analytes changed from year to year, and many VOC measurements were missing. The contents of this table include only those VOCs for which a complete dataset was available for at least 41 buildings.

\begin{tabular}{|c|c|c|c|c|c|}
\hline Compound & $\begin{array}{c}\text { \#of } \\
\text { Buildings }\end{array}$ & $\begin{array}{l}\text { Mean } \\
(p p b)\end{array}$ & $\begin{array}{c}\text { Std Dev } \\
\text { (ppb) }\end{array}$ & $\underset{(p p b)}{\text { Minimum }}$ & $\begin{array}{l}\text { Maximum } \\
(\mathbf{p p b})\end{array}$ \\
\hline 1,2,4-trimethylbenzene & 100 & 0.8 & 0.9 & 0.05 & 7 \\
\hline 1,3,5-trimethylbenzene & 87 & 0.3 & 0.3 & 0.03 & 1.6 \\
\hline 1,4-dichlorobenzene & 100 & 0.5 & 1.3 & 0.03 & 8.1 \\
\hline 1-butanol & 41 & 1.1 & 1.1 & 0.04 & 4.1 \\
\hline 2-butanone & 87 & 2.2 & 1.5 & 0.23 & 9.8 \\
\hline 2-butoxyethanol & 41 & 2.5 & 3.9 & 0.03 & 18 \\
\hline 2-ethylhexanol & 54 & 0.3 & 0.3 & 0.04 & 2.0 \\
\hline 4-ethyltoluene & 87 & 0.3 & 0.3 & 0.03 & 1.9 \\
\hline 4-methyl-2-pentanone & 87 & 0.7 & 1.8 & 0.03 & 15 \\
\hline acetaldehyde & 86 & 4.3 & 2.1 & 1.1 & 9.5 \\
\hline Acetone & 87 & 23 & 14 & 6.0 & 92 \\
\hline a-pinene & 100 & 0.2 & 0.2 & 0.03 & 1.4 \\
\hline Benzene & 100 & 1.5 & 1.2 & 0.27 & 10 \\
\hline butyl acetate & 100 & 0.7 & 1.2 & 0.03 & 6.4 \\
\hline chloromethane & 87 & 1.4 & 0.8 & 0.56 & 7.7 \\
\hline dichlorodifluoromethane & 87 & 2.6 & 5.5 & 0.59 & 49 \\
\hline d-limonene & 100 & 2.0 & 3.0 & 0.06 & 23 \\
\hline Dodecane & 100 & 0.9 & 1.1 & 0.10 & 6.6 \\
\hline ethyl acetate & 100 & 0.9 & 1.7 & 0.05 & 13 \\
\hline ethylbenzene & 100 & 0.6 & 0.5 & 0.06 & 2.6 \\
\hline formaldehyde & 100 & 13 & 6.7 & 2.7 & 36 \\
\hline Hexanal & 41 & 1.3 & 0.8 & 0.29 & 3.5 \\
\hline m \& p-xylenes & 100 & 2.0 & 1.8 & 0.24 & 8.9 \\
\hline Naphthalene & 100 & 1.3 & 4.4 & 0.03 & 34 \\
\hline n-decane & 100 & 0.9 & 1.2 & 0.05 & 8.0 \\
\hline n-hexane & 54 & 1.7 & 3.7 & 0.06 & 28 \\
\hline Nonanal & 54 & 0.6 & 0.4 & 0.14 & 2.0 \\
\hline Nonane & 87 & 0.5 & 1.0 & 0.05 & 8.1 \\
\hline n-undecane & 87 & 1.0 & 1.0 & 0.13 & 5.6 \\
\hline Octane & 100 & 0.6 & 1.7 & 0.05 & 16 \\
\hline o-xylene & 100 & 0.7 & 0.6 & 0.10 & 3.1 \\
\hline Pentanal & 41 & 0.3 & 0.2 & 0.04 & 0.9 \\
\hline Phenol & 41 & 0.6 & 0.5 & 0.11 & 2.2 \\
\hline Styrene & 100 & 0.4 & 0.5 & 0.04 & 3.3 \\
\hline tetrachloroethene & 100 & 0.6 & 1.0 & 0.04 & 6.0 \\
\hline texanol $1 \& 3$ & 41 & 0.6 & 0.7 & 0.02 & 2.7 \\
\hline Toluene & 100 & 4.6 & 8.6 & 0.58 & 82 \\
\hline TXIB & 41 & 0.1 & 0.1 & 0.02 & 0.6 \\
\hline deltaCO (ppm) & 100 & 0.1 & 0.5 & 0.00 & 4.3 \\
\hline
\end{tabular}


Table 2. Summary statistics for environmental and personal variables calculated at the individual-level in the 100 building BASE Study dataset

\begin{tabular}{|c|c|c|c|c|c|c|c|}
\hline \multicolumn{2}{|l|}{ Variable } & \multicolumn{6}{|c|}{ Std. } \\
\hline \multicolumn{8}{|c|}{ Environmental variables } \\
\hline $\mathrm{dCO}_{2}(\mathrm{ppm} / 100)$ & & 4326 & & 1.3 & 0.40 & 6.1 & 2.6 \\
\hline Thermal exposure $\left({ }^{\circ} \mathrm{C}\right.$-hours $)$ & & 4326 & & 6.8 & 2.2 & 43 & 25 \\
\hline $1,2,4$ trimethylbenzene (ppb) & & 4326 & & 1.1 & 0.05 & 6.7 & 0.98 \\
\hline Season $($ winter $=1)$ & & 4326 & $49 \%$ & & & & \\
\hline CA building & & 4326 & $14 \%$ & & & & \\
\hline Carpet in workspace & & 4292 & $89 \%$ & & & & \\
\hline Smoking Building & & 4326 & $25 \%$ & & & & \\
\hline \multicolumn{8}{|c|}{ Personal variables } \\
\hline Current smoker & & 4304 & $15 \%$ & & & & \\
\hline Average $\mathrm{RH}<20 \%$ & & 4326 & $16 \%$ & & & & \\
\hline Female $($ female $=1)$ & & 4295 & $66 \%$ & & & & \\
\hline Age $\geq 40$ yrs & & 4294 & $55 \%$ & & & & \\
\hline Dust allergy (diagnosed) & & 4158 & $32 \%$ & & & & \\
\hline Mold allergy (diagnosed) & & 4093 & $25 \%$ & & & & \\
\hline Hayfever (diagnosed) & & 4073 & $29 \%$ & & & & \\
\hline Combined allergy & & 4208 & $42 \%$ & & & & \\
\hline Migrain (diagnosed) & & 4099 & $21 \%$ & & & & \\
\hline Asthma (diagnosed) & & 4032 & $12 \%$ & & & & \\
\hline Eczema & & 3972 & $9 \%$ & & & & \\
\hline Sensitive to tobacco smoke & & 4263 & $56 \%$ & & & & \\
\hline Sensitive to chemicals & & 4276 & $49 \%$ & & & & \\
\hline Combined sensitive & & 4311 & $67 \%$ & & & & \\
\hline $\begin{array}{l}\text { Any allergy, migraine, } \\
\text { sensitivity }\end{array}$ & eczema, & or 4316 & $81 \%$ & & & & \\
\hline
\end{tabular}


Table 3. Crude and partially ${ }^{\mathrm{b}}$ adjusted prevalence odds ratios ${ }^{\mathrm{a}}(\mathrm{OR})$ for $\mathrm{dCO}_{2}$ and selected MM and LResp SBS symptoms for both the 94-96 and 94-98 BASE dataset analyses.

\begin{tabular}{|c|c|c|c|c|}
\hline \multirow{2}{*}{$\begin{array}{l}\text { SBS } \\
\text { Symptom }\end{array}$} & \multicolumn{2}{|c|}{$\begin{array}{c}\text { 94-96 BASE Dataset } \\
\mathrm{dCO}_{2} \text { OR (per } 100 \text { ppm) }\end{array}$} & \multicolumn{2}{|c|}{$\begin{array}{c}\text { 94-98 BASE Dataset } \\
\mathrm{dCO}_{2} \text { OR (per } 100 \text { ppm) }\end{array}$} \\
\hline & Crude & Adjusted & Crude & Adjusted \\
\hline \multicolumn{5}{|l|}{ MM } \\
\hline Dry eyes & $1.1(1.04-1.23)$ & $1.2(1.06-1.29)$ & $1.0(0.99-1.11)$ & $1.0(0.98-1.12)$ \\
\hline Sore throat & 1.4 (1.21-1.59) & $1.5(1.25-1.72)^{c}$ & $1.2(1.09-1.31)$ & $1.2(1.06-1.29)$ \\
\hline Nose/sinus & $1.1(1.04-1.26)$ & $1.2(1.06-1.34)$ & $1.1(0.98-1.14)$ & $1.1(0.99-1.15)$ \\
\hline LResp & & & & \\
\hline Chest tight & $1.1(0.90-1.41)$ & $1.3(0.96-1.66)$ & $1.0(0.85-1.19)$ & $1.0(0.86-1.21)$ \\
\hline Short breath & $1.1(0.87-1.37)$ & $1.3(0.97-1.69)$ & $1.0(0.87-1.24)$ & $1.1(0.92-1.35)$ \\
\hline Cough & $1.1(0.91-1.23)$ & $1.1(0.90-1.28)$ & $1.0(0.86-1.07)$ & $0.95 \quad(0.85$ \\
\hline Wheeze & $1.4(1.14-1.78)$ & $1.4(1.07-1.84)$ & $1.2(1.02-1.42)$ & $1.2(1.00-1.42)$ \\
\hline
\end{tabular}

${ }^{a}$ Values in parentheses are the $95 \%$ confidence interval (CI). ORs and CIs given in bold are statistically significant at the $95 \%$ confidence level or higher.

${ }^{\mathrm{b}}$ Adjusted for age, sex, presence of carpet in workspace, smoking status, thermal exposure, $\mathrm{RH}$, and 1,2,4 trimethylbenzene. These models did not control for potentially predisposing conditions (e.g., asthma, allergies, chemical sensitivity, etc.).

${ }^{\mathrm{c}} \mathrm{p} \leq 0.005$

Table 4. Means and standard deviations for $\mathrm{dCO}_{2}$ and continuous covariates.

\begin{tabular}{lrrrrr}
\hline & \multicolumn{2}{c}{$94-96$ BASE } & \multicolumn{2}{c}{$97-98$ BASE } \\
Buildings & \multicolumn{2}{c}{ Buildings } \\
Variable & Mean & SD & Mean & \multicolumn{1}{c}{ SD } & P-value $^{\mathrm{a}}$ \\
\hline $\mathrm{dCO}_{2}(\mathrm{ppm})$ & 242 & 142 & 288 & 130 & 0.12 \\
thermal exposure & 26.16 & 6.84 & 24.37 & 6.94 & 0.25 \\
$\mathrm{RH}$ & 40.28 & 8.71 & 44.51 & 10.97 & 0.06 \\
$\mathrm{TMB}$ & 1.28 & 1.31 & 0.93 & 0.96 & 0.17 \\
\hline
\end{tabular}

${ }^{a}$ Student's t-test, 2-sided 
Table 5. Percent of occupants reporting selected characteristics and SBS symptoms.

\begin{tabular}{lcccc}
\hline Variable & $\begin{array}{c}94-96 \\
\text { BASE } \\
\text { Buildings }\end{array}$ & $\begin{array}{c}\text { 97-98 } \\
\text { BASE } \\
\text { Buildings }\end{array}$ & $\begin{array}{c}\text { P4-value } \\
\text { Par }\end{array}$ & $\begin{array}{c}\text { BASE } \\
\text { Buildings }\end{array}$ \\
\hline \% female & 68.0 & 64.8 & 0.04 & 65.9 \\
\% $\geq$ 40 years & 53.2 & 57.5 & 0.01 & 55.3 \\
\% with carpet & 89.9 & 90.5 & 0.50 & 89.1 \\
\% current smoker & 15.5 & 14.0 & 0.24 & 15.2 \\
\% MM & 27.9 & 26.3 & 0.30 & 29.2 \\
\% dry eyes & 20.3 & 18.8 & 0.32 & 18.6 \\
\% sore throat & 7.0 & 6.9 & 0.95 & 6.6 \\
\% nose/sinus & 13.5 & 12.8 & 0.58 & 13.1 \\
\% Lresp & 8.8 & 7.7 & 0.29 & 7.9 \\
\% chest tight & 2.4 & 2.2 & 0.72 & 2.2 \\
\% short breath & 2.3 & 1.5 & 0.12 & 1.8 \\
\% cough & 5.3 & 5.4 & 0.94 & 5.1 \\
\% wheeze & 2.4 & 1.8 & 0.22 & 1.8 \\
\hline
\end{tabular}

${ }^{a}$ Chi-square, Fisher's exact test, two-sided comparison of 94-96 building set and 97-97 building set.

Table 6. Partially adjusted prevalence odds ratios ${ }^{\mathrm{a}}(\mathrm{OR})$ for $\mathrm{dCO}_{2}$ per $100 \mathrm{ppm}$, the California building variable and selected MM and LResp SBS symptoms for the 94-98 BASE dataset analysis.

\begin{tabular}{lll}
\hline $\begin{array}{l}\text { SBS } \\
\text { Symptom }\end{array}$ & $\begin{array}{c}\mathrm{DCO}_{2}(\text { per } 100 \mathrm{ppm}) \\
\text { OR }\end{array}$ & $\begin{array}{c}\text { California Building } \\
\text { OR }\end{array}$ \\
\hline \multicolumn{1}{c}{ MM } & $\mathbf{1 . 1 ( 1 . 0 1 - 1 . 1 4 )}$ & $\mathbf{1 . 3 ( 1 . 0 1 - 1 . 5 9 )}$ \\
Dry eyes & $1.1(1.00-1.14)$ & $1.2(0.95-1.59)$ \\
Sore throat & $\mathbf{1 . 2 ( 1 . 0 9 - 1 . 3 5 )}$ & $1.5(0.98-2.18)$ \\
Nose/sinus & $\mathbf{1 . 1 ( 1 . 0 2 - 1 . 1 9 )}$ & $\mathbf{1 . 4}(\mathbf{1 . 0 7 - 1 . 9 2 )}$ \\
$\quad$ Lresp & $1.1(0.96-1.17)$ & $1.3(0.94-1.92)$ \\
Chest tight & $1.1(0.90-1.29)$ & $1.8(0.94-3.28)$ \\
Short breath & $1.1(0.91-1.38)$ & $1.1(0.48-2.37)$ \\
Cough & $1.0(0.85-1.09)$ & $1.1(0.72-1.74)$ \\
Wheeze & $\mathbf{1 . 3 ( 1 . 0 4 - 1 . 5 1 )}$ & $1.7(0.80-3.42)$ \\
\hline
\end{tabular}

${ }^{\mathrm{a}}$ Values in parentheses are the $95 \%$ confidence interval (CI). ORs and CIs given in bold are statistically significant at the $95 \%$ confidence level or higher.

${ }^{b}$ Estimating the association between being a "California Building" and SBS symptoms. 
Table 7. Statistically significant ( $95 \%$ confidence level) covariates in the sensitive-population adjusted logistic regression model. A "+" signifies odds ratio point estimates greater than unity while a "-" represents those less than unity.

\begin{tabular}{|c|c|c|c|c|c|c|c|c|c|}
\hline \multirow[b]{2}{*}{ Covariate } & \multicolumn{9}{|c|}{ SBS Symptom } \\
\hline & MM & $\begin{array}{l}\text { Dry } \\
\text { eyes }\end{array}$ & $\begin{array}{c}\text { Sore } \\
\text { Throat }\end{array}$ & $\begin{array}{c}\text { Nose/ } \\
\text { sinus }\end{array}$ & LResp & $\begin{array}{l}\text { Chest } \\
\text { tight }\end{array}$ & $\begin{array}{r}\text { Short } \\
\text { breath }\end{array}$ & Cough & Wheeze \\
\hline $\mathrm{dCO}_{2}$ & & & + & & & & & & \\
\hline Female & + & + & + & + & + & + & + & + & \\
\hline Age $>40$ & & & + & & & & & & \\
\hline Carpet & & & & - & & & & & \\
\hline \multicolumn{10}{|l|}{ Smoker } \\
\hline Therm. Exp & & & & & & & - & & \\
\hline $\mathrm{RH}<20$ & & & + & & & + & & & \\
\hline $1,2,4 \mathrm{TMB}$ & & & & & + & & + & & \\
\hline \multicolumn{10}{|l|}{ CA Bldg } \\
\hline Dust allergy & & & + & & + & & & + & \\
\hline Mold allergy & + & + & & + & & & + & & + \\
\hline Migrain & + & + & & & + & & & & \\
\hline Asthma & & & & & + & + & + & + & + \\
\hline Eczema & & & & & + & & & & \\
\hline Hayfever & + & + & & + & & & & & \\
\hline Tobacco Sens. & & & & - & & - & & & \\
\hline Chemical Sens. & + & + & + & + & + & + & + & + & + \\
\hline \multicolumn{10}{|l|}{ Season } \\
\hline Sample Size & 3749 & 3692 & 3714 & 3661 & 3754 & 3747 & 3736 & 3715 & 3743 \\
\hline
\end{tabular}

Table 8 . Statistically significant ( $95 \%$ confidence level) covariates in the sensitive-population adjusted logistic regression model. A "+" signifies odds ratio point estimates greater than unity while a "-" represents those less than unity.

\begin{tabular}{|c|c|c|c|c|c|c|c|c|c|}
\hline \multirow[b]{2}{*}{ Covariate } & \multicolumn{9}{|c|}{ SBS Symptom } \\
\hline & MM & $\begin{array}{l}\text { Dry } \\
\text { eyes }\end{array}$ & $\begin{array}{c}\text { Sore } \\
\text { Throat }\end{array}$ & $\begin{array}{c}\text { Nose/ } \\
\text { sinus }\end{array}$ & LResp & $\begin{array}{l}\text { Chest } \\
\text { tight }\end{array}$ & $\begin{array}{l}\text { Short } \\
\text { breath }\end{array}$ & Cough & Wheeze \\
\hline $\mathrm{dCO}_{2}$ & & + & + & + & & & & & + \\
\hline Female & + & + & + & + & + & + & + & + & \\
\hline Age $>40$ & & + & + & & + & & & + & \\
\hline \multicolumn{10}{|l|}{ Carpet } \\
\hline Smoker & & & & + & + & & & & + \\
\hline Therm. Exp & & + & & & & & & & \\
\hline $\mathrm{RH}<20$ & & & + & & & + & & & \\
\hline $1,2,4 \mathrm{TMB}$ & & & & & & & + & & \\
\hline CA Bldg & & & & + & & + & & & \\
\hline ANYSENS & + & + & + & + & + & + & + & + & + \\
\hline \multicolumn{10}{|l|}{ Season } \\
\hline Sample size & 4221 & 4152 & 4167 & 4108 & 4225 & 4210 & 4195 & 4169 & 4207 \\
\hline
\end{tabular}


Table 9. Crude and adjusted prevalence odds ratios ${ }^{\mathrm{a}}(\mathrm{OR})$ for $\mathrm{dCO}_{2}$, sex, and any environmental sensitivity, and MM and LResp SBS symptoms for the 94-98 BASE dataset analyses.

\begin{tabular}{|c|c|c|c|c|}
\hline \multirow{3}{*}{$\begin{array}{l}\text { SBS } \\
\text { Symptom }\end{array}$} & \multicolumn{4}{|c|}{ 94-98 BASE Dataset } \\
\hline & \multicolumn{2}{|c|}{$\mathrm{dCO}_{2} \mathrm{OR}($ per $100 \mathrm{ppm})$} & \multicolumn{2}{|c|}{ Individual risk factors } \\
\hline & Crude & Adjusted $^{c}$ & Female $^{\mathrm{d}}$ & ANYSENS \\
\hline MM & $1.0(0.99-1.090$ & $1.1(1.00-1.12)$ & $2.1(1.8-2.4)^{b}$ & $1.9(1.5-2.3)^{b}$ \\
\hline Dry eyes & $1.0(1.00-1.12)$ & $1.1(1.06-1.14)$ & $2.2(1.8-2.6)^{b}$ & $2.1(1.7-2.7)^{b}$ \\
\hline Sore throat & $1.1(1.05-1.25)^{b}$ & $1.2(1.06-1.30)^{b}$ & $2.1(1.5-2.9)^{b}$ & $2.2(1.5-3.4)^{b}$ \\
\hline Nose/sinus & $1.0(0.98-1.11)$ & $1.1(1.02-1.20)$ & $1.8(1.4-2.2)^{b}$ & $2.4(1.7-3.2)^{b}$ \\
\hline LResp & $1.0(0.94-1.12)$ & $1.1(0.96-1.17)$ & $1.7(1.3-2.3)^{b}$ & $2.7(1.8-4.1)^{b}$ \\
\hline Chest tight & $1.0(0.89-1.20)$ & $1.1(0.95-1.35)$ & 1.8 (1.1-3.1) & $11.4(2.8-46.5)^{b}$ \\
\hline Short breath & $1.0(0.89-1.24)$ & $1.1(0.93-1.39)$ & $3.0(1.5-5.9)^{b}$ & $5.5(1.7-17.8)^{b}$ \\
\hline Cough & $1.0(0.88-1.08)$ & $0.99(0.87-1.11)$ & $1.8(1.3-2.5)^{b}$ & $1.9(1.2-3.0)^{b}$ \\
\hline Wheeze & $1.2(1.04-1.42)$ & $1.2(1.03-1.50)$ & $1.7(0.9-3.0)$ & $2.5(1.2-6.0)$ \\
\hline
\end{tabular}

${ }^{a}$ Values in parentheses are the $95 \%$ confidence interval (CI). ORs and CIs given in bold are statistically significant at the $95 \%$ confidence level or higher.

${ }^{\mathrm{b}} \mathrm{p} \leq 0.005$

${ }^{\mathrm{c}}$ Adjusted for the following potential confounders: sex, age $\geq 40$, carpet in workspace, smoker, thermal exposure, $\mathrm{RH}<20 \%, 1,2,4$ trimethylbenzene, CA building, any sensitivity, and season

${ }^{\mathrm{d}}$ Adjusted odds ratio for females vs. males of having the SBS symptoms

${ }^{\mathrm{e}}$ One or more of the following potentially predisposing condition: dust allergy, mold allergy, hayfever, eczema, asthma, migrane, sensitivity to (environmental) tobacco smoke, chemical sensitivity. 
Table 10. Results of Principal Components Analysis of the 100 Building BASE Study VOC set plus deltaCO. The compounds are sorted by loading from first to last principal component. Values in bold typeface indicate compounds with higher loading in each principal component. Principal components PC1 through PC 7 have Eigenvalues $>1.0$.

\begin{tabular}{|c|c|c|c|c|c|c|c|c|c|c|c|}
\hline \multirow[b]{2}{*}{100 Building VOC set } & \multicolumn{11}{|c|}{ Rotated Principal Components } \\
\hline & PC1 & PC2 & PC3 & PC4 & PC5 & PC6 & PC7 & PC8 & PC9 & PC10 & $\begin{array}{l}\text { Comm- } \\
\text { unality }\end{array}$ \\
\hline o-xylene & 0.94 & 0.16 & 0.22 & 0.03 & 0.04 & 0.03 & 0.02 & 0.06 & 0.02 & 0.01 & 0.97 \\
\hline m \& p-xylenes & 0.93 & 0.12 & 0.24 & 0.03 & 0.00 & 0.04 & 0.04 & -0.03 & 0.04 & 0.00 & 0.95 \\
\hline ethylbenzene & 0.90 & 0.14 & 0.15 & 0.01 & 0.03 & 0.00 & 0.03 & -0.06 & 0.03 & -0.04 & 0.87 \\
\hline Benzene & 0.58 & 0.02 & -0.11 & 0.48 & 0.10 & 0.33 & 0.16 & 0.12 & 0.01 & 0.09 & 0.75 \\
\hline ethyl acetate & 0.02 & 0.90 & 0.02 & -0.05 & 0.03 & -0.08 & 0.12 & 0.01 & 0.06 & 0.03 & 0.83 \\
\hline Toluene & 0.47 & 0.70 & 0.03 & 0.13 & -0.01 & 0.03 & -0.01 & 0.10 & -0.11 & 0.01 & 0.75 \\
\hline butyl acetate & 0.44 & 0.62 & -0.05 & -0.11 & -0.03 & 0.30 & -0.06 & 0.26 & 0.08 & 0.00 & 0.76 \\
\hline Styrene & 0.19 & 0.03 & 0.80 & 0.30 & 0.22 & -0.05 & -0.05 & -0.10 & 0.05 & -0.10 & 0.85 \\
\hline 1,2,4-trimethylbenzene & 0.46 & 0.04 & 0.70 & 0.08 & 0.04 & 0.18 & 0.14 & 0.11 & -0.07 & 0.07 & 0.79 \\
\hline naphthalene & 0.03 & -0.02 & 0.27 & 0.81 & -0.09 & -0.07 & 0.01 & -0.10 & 0.12 & -0.01 & 0.77 \\
\hline d-limonene & -0.02 & 0.06 & 0.12 & -0.06 & 0.86 & 0.10 & -0.15 & -0.03 & 0.11 & -0.10 & 0.83 \\
\hline Dodecane & 0.07 & -0.07 & 0.05 & 0.59 & 0.64 & -0.08 & 0.26 & 0.14 & -0.12 & 0.03 & 0.87 \\
\hline n-decane & 0.28 & -0.11 & 0.33 & -0.29 & 0.43 & 0.05 & 0.20 & 0.10 & 0.12 & 0.29 & 0.63 \\
\hline DeltaCO & 0.31 & 0.12 & -0.03 & -0.09 & 0.14 & 0.72 & -0.08 & 0.02 & -0.22 & 0.00 & 0.71 \\
\hline Octane & 0.51 & 0.20 & -0.18 & -0.05 & 0.07 & -0.64 & -0.14 & -0.04 & -0.25 & 0.03 & 0.83 \\
\hline 1,4-dichlorobenzene & 0.03 & 0.11 & 0.04 & 0.09 & -0.04 & 0.02 & 0.87 & -0.12 & 0.08 & -0.09 & 0.81 \\
\hline a-pinene & -0.03 & 0.18 & -0.02 & -0.02 & 0.03 & 0.07 & -0.13 & 0.88 & 0.06 & -0.07 & 0.84 \\
\hline tetrachloroethene & 0.16 & -0.16 & 0.43 & -0.07 & -0.01 & -0.19 & 0.42 & 0.47 & -0.25 & 0.09 & 0.75 \\
\hline formaldehyde & 0.06 & 0.03 & -0.01 & 0.06 & 0.08 & -0.07 & 0.05 & 0.03 & 0.94 & 0.07 & 0.92 \\
\hline 1,1,1-trichloroethane & -0.02 & 0.04 & -0.01 & 0.01 & -0.05 & -0.01 & -0.08 & -0.06 & 0.06 & 0.95 & 0.92 \\
\hline $\begin{array}{r}\text { Standardized variance } \\
\text { explained: }\end{array}$ & $26 \%$ & $11 \%$ & $7 \%$ & $\%$ & $6 \%$ & $6 \%$ & $6 \%$ & $5 \%$ & $4 \%$ & $4 \%$ & $\begin{array}{r}\text { Total }= \\
82 \%\end{array}$ \\
\hline
\end{tabular}


Table 11. Possible VOC source identification for 11 principal components (eigenvalues $>1$ ) of the 41 building BASE study VOC set.

\begin{tabular}{|c|c|c|c|c|}
\hline PC & $\begin{array}{c}\text { Major contributors } \\
\text { (loading } \geq \mathbf{0 . 5} \text { ) }\end{array}$ & $\begin{array}{c}\text { Secondary contributors } \\
(\text { loading }<0.5)\end{array}$ & Possible source & References \\
\hline PC1 & $\begin{array}{l}\text { pentanal, hexanal, phenol, 1-butanol, } \\
\text { styrene, 4-methyl-2-pentanone, } \\
\text { acetaldehyde }\end{array}$ & $\begin{array}{l}\text { nonanal, texanol } 1 \& 3 \text {, acetone, } \\
\text { formaldehyde, butyl acetate }\end{array}$ & Furniture coatings & {$[1]$} \\
\hline PC2 & $\begin{array}{l}\text { 1,2,4-trimethylbenzene, } 1,3,5- \\
\text { trimethylbenzene, } 4 \text {-ethyltoluene, } \\
\text { toluene, benzene }\end{array}$ & $\begin{array}{l}\text { Ethylbenzene, } \mathrm{m} \& \mathrm{p} \text {-xylenes, o-xylene, n- } \\
\text { undecane, nonane, } \mathrm{n} \text {-decane, } \\
\text { tetrachloroethene, 1,4-dichlorobenzene, } \\
\text { deltaCO, naphthalene, butyl acetate, } \\
\text { acetadldehyde }\end{array}$ & $\begin{array}{l}\text { Construction materials } \\
\text { including ceiling panels and } \\
\text { some insulation }\end{array}$ & {$[2],[3]$} \\
\hline PC3 & $\begin{array}{l}\text { ethylbenzene, octane, } \mathrm{m} \& \text { p-xylenes, } \\
\text { o-xylene, n-hexane }\end{array}$ & toluene, 1,1,1-trichloroethane & $\begin{array}{l}\text { Motor vehicles (MV), printing, } \\
\text { printed matter (Prnt) }\end{array}$ & $\begin{array}{l}\text { MV: [4] } \\
\text { Prnt: [5], [6] }\end{array}$ \\
\hline PC4 & $\begin{array}{l}\text { dichlorodifluoromethane, d-limonene, } \\
\text { dodecane, n-undecane }\end{array}$ & hexanal, styrene & Carpet, under-carpet. & {$[7],[2],[8]$} \\
\hline PC5 & TXIB, ethyl acetate, texanol $1 \& 3$ & nonanal, 2-butoxyethanol, butyl acetate & Paint & $\begin{array}{l}\text { [2], [9], [10], } \\
{[11]}\end{array}$ \\
\hline PC6 & acetone, formaldehyde & $\begin{array}{l}\text { 1-butanol, hexane, 1,1,1-trichloroethane, } \\
\text { acetaldehyde }\end{array}$ & Draperies fabric coverings & {$[8]$} \\
\hline PC7 & nonane, $\mathrm{n}$-decane & & Wood finishing products & [12] \\
\hline PC8 & Tetrachloroethene & hexane, n-undecane & Vinyl Flooring & {$[2]$} \\
\hline PC9 & $\begin{array}{l}\text { 4-methyl-2-pentanone, 1,1,1- } \\
\text { trichloroethane }\end{array}$ & & Adhesives, automotive products & {$[13]$} \\
\hline PC10 & chloromethane & Nonanal & $\begin{array}{l}\text { Chlorinated material or tap } \\
\text { water }\end{array}$ & \\
\hline PC11 & 2-butanone & & Solvents & [13] \\
\hline
\end{tabular}

References: [1] Salthammer (1997); [2] Tirkkonen et al. (1993); [3] Park et al. (1996); [4] Chang-Chen et al. 1991; [5] Wolkoff et al. 1993 ; [6] Wadden et al. 1995; [7] Kirchner et al.(1993); [8] Bayer and Papanicolopoulos (1990) [9] Plen (1990); [10] Wilkes et al. (1996); [11] Clausen et al. (1990); [12] Chang and Guo (1992);[13] Sack et al. (1992) 
Table 12. 100 building PCA source identification cross-referenced and guided by the results from the 41 building PCA analyses. Note that PC1 through PC7 have eignevalues $>1.0$.

\begin{tabular}{|ccl|}
\hline $\begin{array}{c}\text { 100 Bld. } \\
\text { PCA }\end{array}$ & $\begin{array}{c}\text { 41 Bld. } \\
\text { PCA }\end{array}$ & \multicolumn{1}{c|}{ Possible VOC sources } \\
\hline PC1 & PC3 & Furniture coatings \\
PC2 & PC5 & Paint \\
PC3 & PC2 & Construction materials \\
PC4 & PC3 & Printing processes, printed materials \\
PC5 & PC4 & Carpet, under-carpet \\
PC6 & & Attached parking garage \\
PC7 & & Cleaning products \\
PC8 & PC8 & Vinyl Flooring \\
PC9 & & Unidentified formaldehyde sources \\
PC10 & PC9 & Adhesives \\
\hline
\end{tabular}

Table 13. Prevalence odds ratio point estimates for statistically significant (95\% confidence level) $\mathrm{dCO}_{2}$ and $\mathrm{PC}$ covariates PC1 - PC7 added to the sensitive-population adjusted ${ }^{\mathrm{a}}$ logistic regression model. Note that the PC vectors are non-dimensional and therefore the units for these ORs are not well defined.

\begin{tabular}{|l|c|c|c|c|c|c|c|c|c|}
\hline $\begin{array}{c}\text { SBS } \\
\text { Symptom } \\
\text { /covariate }\end{array}$ & MM & $\begin{array}{c}\text { Dry } \\
\text { eyes }\end{array}$ & $\begin{array}{c}\text { Sore } \\
\text { Throat }\end{array}$ & $\begin{array}{l}\text { Nose } \\
\text { /sinus }\end{array}$ & LResp & $\begin{array}{c}\text { Chest } \\
\text { tight }\end{array}$ & $\begin{array}{c}\text { Short } \\
\text { breath }\end{array}$ & Cough & Wheeze \\
\hline $\mathrm{dCO}_{2}$ & 1.07 & 1.07 & 1.17 & 1.09 & & & & & 1.24 \\
\hline PC1 & & & & & & & 1.33 & & \\
\hline PC2 & & & & & & & & & \\
\hline PC3 & 1.08 & 1.08 & & & & & 1.21 & & \\
\hline PC4 & & & & & & & & & \\
\hline PC5 & 0.89 & & & & 0.84 & & & 0.82 & \\
\hline PC6 & 0.91 & & & 0.86 & & & & & \\
\hline PC7 & & & & & & & & & \\
\hline $\begin{array}{r}\text { Sample } \\
\text { size }\end{array}$ & 4221 & 4152 & 4167 & 4108 & 4225 & 4210 & 4195 & 4169 & 4207 \\
\hline
\end{tabular}

${ }^{a}$ Adjusted for the following potential confounders: gender, age $\geq 40$, carpet in workspace, smoker, thermal exposure, $\mathrm{RH}<20 \%$, CA building, any sensitivity, and season 
Table 14. Prevalence odds ratio point-estimates for statistically significant (95\% confidence level) $\mathrm{dCO}_{2}$, indoor VOCs, and deltaCO for the 100 building VOC set, added to the sensitive-population adjusted ${ }^{\mathrm{a}}$ logistic regression model. Note that the VOCs odds ratios are per-ppb, while the deltaCO is per-ppm, and the $\mathrm{dCO}_{2}$ is per $100 \mathrm{ppm}$.

\begin{tabular}{|l|ccccccc|}
\hline \multicolumn{1}{|c|}{$\begin{array}{c}\text { Compound / } \\
\text { symptom }\end{array}$} & MM $\begin{array}{c}\text { Dry } \\
\text { eyes }\end{array}$ & $\begin{array}{c}\text { Sore } \\
\text { Throat }\end{array}$ sose/ & \multicolumn{3}{c|}{$\begin{array}{c}\text { Chest } \\
\text { sinus }\end{array}$} & LResp & tight \\
breath Cough Wheeze
\end{tabular}

${ }^{a}$ Adjusted for the following potential confounders: gender, age $\geq 40$, carpet in workspace, smoker, thermal exposure, $\mathrm{RH}<20 \%$, CA building, any sensitivity, and season. 


\section{FIGURES}

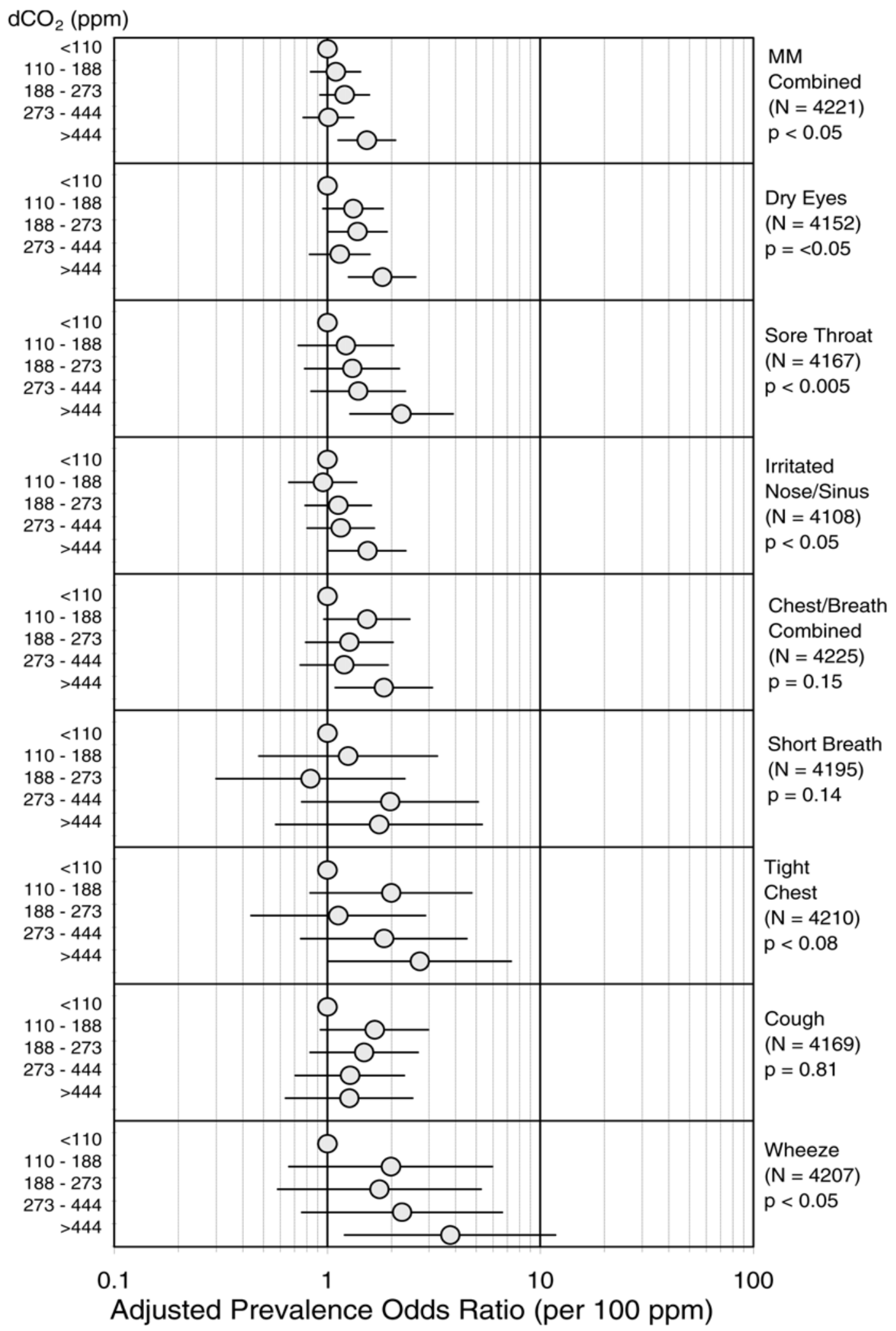

Figure 1. Dose response relationship between binned $\mathrm{dCO}_{2}$ and $\mathrm{MM}$ and LResp symptoms in 100 BASE study buildings. ORs and 95\% CIs shown are the results of adjusted models including the ANYSENS variable. $\mathrm{DCO}_{2}$ bins reflect the $10^{\text {th }}$ and $90^{\text {th }}$ percentiles of the $\mathrm{dCO}_{2}$ distribution, and three bins evenly split between them. . P-values shown reflect the fit of the dose-response model with smaller $p$-values indicating a better fit 1 . 